\title{
Современные тенденции реабилитации антропогенных территорий
}

\author{
Е.Ю.Прокофьева, МАРХИ, Москва. \\ Н.В.Васильев, МАРХИ, Москва.
}

В настоящее время в мире формируется тенденция к реабилитации антропогенных ландшафтов в городской среде. Это связано с постоянным развитием городов, изменением производственных технологий в различных сферах, задачами по улучшению качества жизни населения в городах. Процессы индустриализации и урбанизации ландшафта, происходившие в XX веке и продолжающиеся в настоящее время, привели не только к отрицательным экологическим, экономическим и социальным последствиям для большинства городских территорий, но и к отчуждению урбанизированного пространства от жителей. Переориентация экономического развития городов, сопровождаемая тенденцией закрытия или вывода индустриальных производств за границы города, определяет необходимость поиска новых направлений использования этих территорий. Статья посвящена актуальной теме реабилитации и реконструкции антропогенного ландшафта городской среды с точки зрения устойчивого развития и повышения его рекреационной привлекательности. Особое внимание уделено современным подходам в мировой практике для осуществления экологической реконструкции постиндустриальных ландшафтов в городе. Распространяясь на общественные и коллективные пространства улиц, дворов, скверов, площадей, формируя культурный ландшафт нового качества на месте бывшего промышленного производства, ландшафтные преобразования позволяют решить важнейшую задачу реновации городской среды. Пассивные промышленные территории занимают значительную часть наиболее привлекательных с инвестиционной точки зрения районов города. Такие зоны являются потенциалом для градостроительного развития. В статье также сформулированы основные принципы реабилитации и реновации бывших промышленных территорий, основной целью которых является устойчивое развитие и формирование комфортной городской среды.

Ключевые слова: нарушенные территории, реабилитация, урбанизированный ландшафт, антропогенные территории, городская среда, реновация, ландшафтная архитектура, ландшафтное проектирование, устойчивое развитие.

\section{Modern Trends of Rehabilitation of Anthropogenic Territories}

E.Yu.Prokofyeva, MARHI, Moscow

N.V.Vasiliev, MARHI, Moscow

Currently, there is a tendency to rehabilitate, anthropogenic landscapes in the urban environment. This is due to the continuing development of cities, changes in production technologies in various areas, the tasks to improve the quality of life of the population in cities. The processes of industrialization and urbanization of the landscape, which took place in the $X X$ century and continue today, have led not only to negative environmental, economic and social consequences for most urban areas but also to the alienation of urban space from residents. The reorientation of the economic development of cities, accompanied by the tendency to close or withdraw industrial production outside the city limits, determines the need to find new directions for the use of these territories. The article is devoted to the actual topic of rehabilitation and reconstruction of the anthropogenic landscape of the urban environment from the point of view of sustainable development and increasing its recreational attractiveness. Special attention paid to modern approaches in world practice for the ecological reconstruction of post-industrial landscapes in the city. Extending to public and collective spaces of streets, yards, squares, forming a cultural landscape of new quality on the site of former industrial production, landscape transformations allow solving the most important task of urban environment renovation. Passive industrial areas occupy a significant part of the most attractive areas of the city from an investment point of view. Such zones have the potential for urban development. The article also formulated the basic principles of rehabilitation and renovation of former industrial areas, the main purpose of which is sustainable development and the formation of a comfortable urban environment.

Keywords: disturbed areas, rehabilitation, urban landscape, anthropogenic areas, urban environment, renovation, landscape architecture, landscape design, sustainable development.

Процессы индустриализации и урбанизации ландшафта, происходившие в XX веке и продолжающиеся в настоящее время, привели не только к отрицательным экологическим, экономическим и социальным последствиям для большинства городских территорий, но и к отчуждению урбанизированного пространства от жителей. Такие территории - антропогенные, представляют собой сильно изменённые и преобразованные хозяйственной деятельностью, индустриальными и транспортными объектами и сооружениями городские пространства. На территориях такого типа существуют антропогенные объекты, созданные человеком и изменённые в результате хозяйственной или иной деятельности. Антропогенные территории, по 
степени воздействия делятся на: условно изменённые территории; слабо изменённые территории; сильно изменённые или нарушенные территории; собственно-культурные, или рационально преобразованные ландшафты. Также антропогенные ландшафты можно классифицировать по целенаправленности их возникновения: прямые антропогенные ландшафты - возникающие в результате целенаправленной хозяйственной деятельности человека, изначально запланированные комплексы; сопутствующие антропогенные комплексы - не созданные человеком напрямую. Возникают в результате косвенного хозяйственного воздействия.

Основной целью градостроительной реабилитации и освоения антропогенных территорий является обеспечение условий устойчивого развития городской среды и формирование благоприятной среды жизнедеятельности для населения $[1 ; 2]$. Новая ориентация экономического и социального развития городов характеризуется тенденцией закрытия или вывода индустриальных производств за пределы города, что определило необходимость выявления новых функций и направлений использования и дальнейшего развития этих территорий.

В настоящее время в мире формируется тенденция к реабилитации антропогенных ландшафтов в городской среде. Это связано с постоянным развитием городов, изменением производственных технологий в различных сферах, задачами по улучшению качества жизни населения в городах. Реабилитация и реконструкция нарушенного антропогенного ландшафта в урбанизированной среде рассматривается в контексте устойчивого развития и повышения рекреационной привлекательности территорий. В связи с этим особое внимание необходимо уделить изучению и всестороннему анализу современных подходов и тенденций в мировой практике к преобразованию постиндустриальных ландшафтов в городской среде. Распространяясь на общественные пространства в виде площадей, улиц, скверов, формируя культурный ландшафт совершенно нового качества на месте бывшего промышленного производства, ландшафтные преобразования позволяют решить основную задачу реновации урбанизированной среды. Ключевые приемы - организация городских ландшафтных объектов с учётом требований экологии, экономики, социальной составляющей, эстетики. Экономические возможности настоящего времени достаточно ограничены, таким образом, строительство садов и парков традиционного типа для целей реабилитации становиться затруднительным. Сложившаяся ситуация вынуждает искать новые пути и решения, не прибегая к созданию крупномасштабных объектов, а перераспределяя средства на ландшафтную организацию локальных фрагментов города, являющихся источниками экологической напряженности.

Негативное воздействие техногенного характера на окружающую среду усугубляется проблемами недостаточного государственного регулирования охраны окружающей среды и контроля за нарушенными антропогенными территориями. Такая политика действий влечёт за собой ухудшение экологи- ческой, экономической и социальной ситуации на локальных участках урбанизированной среды.

Анализ урбанизированной среды выявил следующие проблемы:

- деградация механического и биологического состояния территории в зависимости от антропогенной типологии территории;

- нарастающее загрязнение окружающей городской среды вследствие пассивного состояния нарушенных территорий;

- существенное сокращение экологического и экономического потенциала развития территории;

- отсутствие законов и принципов, формирующих и регулирующих ситуацию с антропогенными территориями в городской среде;

- отсутствие взаимосвязи существующих и планируемых архитектурных сооружений с потребностями населения;

- преобладающий аскетизм и утилитаризм в градостроительной практике.

Формулировка ключевых проблем реабилитации антропогенного ландшафта позволяет подойти к выявлению новых возможностей ландшафтной архитектуры для достижения оптимального соотношения естественных и искусственных компонентов урбанизированной среды. При этом необходимо уделить пристальное внимание элементам городской среды, которые должны удовлетворять эстетическим, функциональным, социальным и культурным потребностям населения и способствовать созданию благоприятных условий для жизнедеятельности [3]. Обоснованная и выработанная стратегия развития территорий, планомерная организация взаимодействия общества с природной составляющей - новый этап использования антропогенного ландшафта.

Инновационные подходы в ландшафтном проектировании прежде всего ориентированы на динамичные и познавательные интенции современного человека. Прямым следствием качественной и количественной реабилитации территорий в городской среде является увеличение степени свободы при размещении различных тематических участков озеленённой территории и при организации пешеходного движения. Расширяется вариативность наполнения частей территории, приспособленной для различных видов отдыха, появляются новые тематические и функциональные сценарии. Природный ландшафт дополняется искусственными элементами, используются все возможности и приёмы ландшафтной архитектуры, такие как: геопластика, моделирование растительности, освещение, конструирование гидрогеологических объектов [4]. Для решения имеющихся проблем урбанизированной среды используются инновационные подходы ландшафтного дизайна.

Современные тенденции в формировании устойчивой урбанизированной среды в контексте нарушенных территорий:

- превращение исторических индустриальных ландшафтов в устойчивые фрагменты городской среды; 
- максимальное соответствие ландшафтных и архитектурных компонентов новым функциям пространства;

- преобладание естественных материалов над искусственными в оформлении городских пространств;

- создание средствами ландшафтной архитектуры природообразных элементов вблизи источников экологической напряжённости в городской среде;

- обеспечение необходимости стабилизации и улучшения экологического состояния нарушенных и близлежащих территорий;

- эффективное использование и конверсия сохранившихся природного потенциала и ресурсов.

Главной задачей реабилитации или реновации антропогенных ландшафтов является изменение функционального назначения с целью повышения экономической, экологической и социальной эффективности режима использования территории. Промышленные зоны, давно существующие в структурах городов, располагаются в большинстве случаев в центральной части города, так как изначально производство и промышленность были основными градообразующими факторами. В настоящее время многие города имеют тенденцию к постиндустриальному развитию, и этот процесс напрямую связан с необходимостью реорганизации недействующих и устаревших промышленных зон, которые занимают привлекательные с инвестиционной точки зрения и перспективные городские территории.

Процессы реабилитации и реновации бывших антропогенных ландшафтов приобретают всё большую актуальность и популярность Этот процесс многогранен и сложен как в административном, так и в социально-экономическом аспектах.

Больше половины различных нарушенных территорий имеют по нескольку собственников, планы которых по освоению этих территорий могут разниться, поэтому основная задача государственного регулирования - не только заинтересовать владельцев, но и создать благоприятные условия для инвестиции.

Существует несколько зависящих от ряда факторов направлений развития и реабилитации бывших промышленных

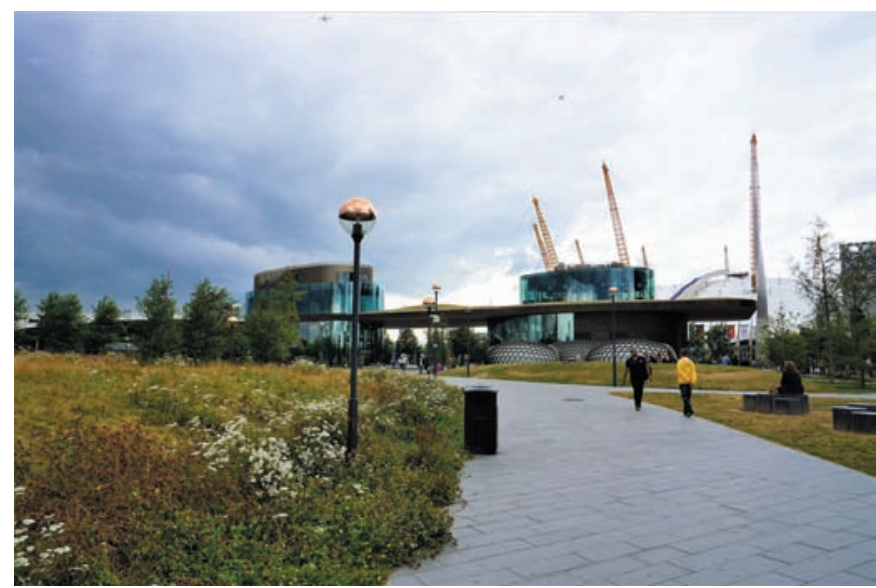

Рис. 1. Олимпийский парк в Лондоне. Фото Е.Ю. Прокофьевой территорий. Это: расположение, индустриальное наследие, степень вовлечённости в городскую среду, программа инвестиций.

\section{Преобразование ландшафтов в новые парковые территории}

Восстановление естественного каркаса города играет важную роль в создании здоровой и полноценной среды жизнедеятельности. В крупных городах рекреационная нагрузка постоянно увеличивается, и в результате постоянного развития и увеличения площади городов природные территории дробятся и подвергаются новому антропогенному воздействию, что приводит к их стагнации и деградации. Вследствие этого рекреационная реновация и новое использование бывших производственных индустриальных зон обладает наилучшим потенциалом, направленным на оздоровление и ревитализацию городской среды. Один из примеров - Олимпийский парк в Лондоне (рис. 1). Парк, построенный на месте бывших заводов и рабочих кварталов, стал удачным примером архитектурно-ландшафтной конверсии территории с индустриальным прошлым. Решение о постройке парка является также примером апробации мирового опыта дальнейшей эксплуатации спортивных сооружений после проведения спортивных мероприятий. Таким образом, удалось избежать негативный опыт грядущих и предшествующих спортивных мероприятий, когда объекты в Греции (Олимпийские игры, 2004) и Бразилии (Чемпионат мира по футболу, 2014) по прошествии времени превратились в неблагоприятные антропогенные территории. Их пассивное использование отрицательно влияет на окружающую городскую среду, которая требует реабилитации и реновации. Пример в Лондоне иллюстрирует архитектурно-ландшафтную реабилитацию территории с гармоничной интеграцией её в урбанизированную среду. Успешно решить поставленную задачу позволил постепенный вывод предприятий за городскую черту и дальнейшее планомерное восстановление территории с использованием

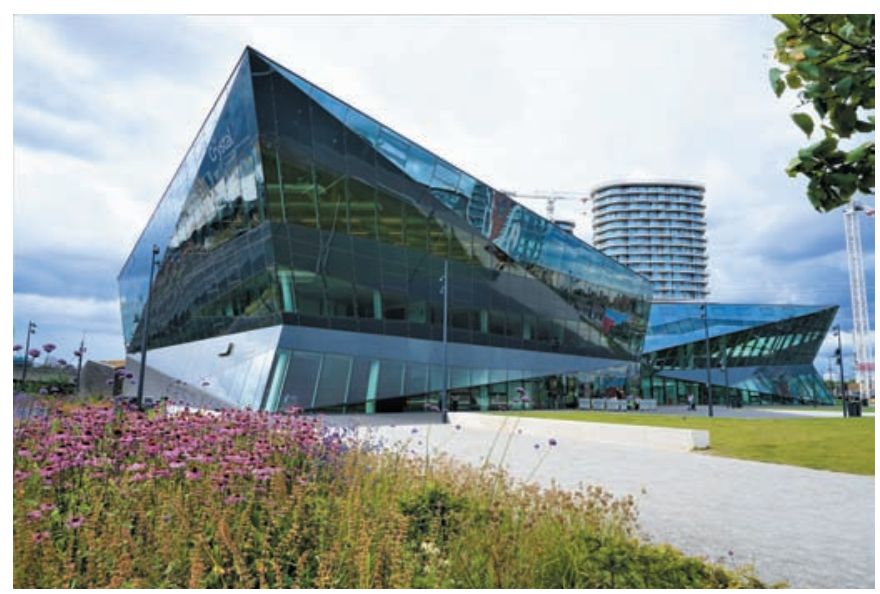

Pис. 2. Здание «Кристалл» (The Crystal). Фото Е.Ю. Прокофьевой 
последний научных и технических наработок. Важно также отметить, что Олимпийский парк был первым за последние сто лет лондонским парком, открывшимся в городской черте.

В соседнем районе, на берегу Темзы расположен деловой квартал, построенный в конце 90-х годов прошлого века на месте антропогенных территорий в периферийной на тот момент части города и интегрированный в городскую среду. Данная территория соединяется с Олимпийским парком канатной дорогой, являющейся на сегодняшней день важной частью транспортной системы города. Ещё двадцать лет назад на этом месте были заброшенные доки, а сегодня здесь общественно-деловая застройка, гармонично чередующаяся с природными зонами. Здесь же расположено инновационное энергоэффективные здание «Кристалл» (The Crystal) (рис. 2), построенное компанией «Siemens» с применением «зелёных технологий». Это пример грамотного подхода к планированию всего района с использованием комплекса архитектурноландшафтных мероприятий для превращения пустынной окраины с индустриальным прошлым в полноценную часть городской среды.

Другим примером удачной реабилитации, наглядно демонстрирующей актуальность и для современной истории, - Олимпийский парк в Мюнхене (1972), построенный на месте бывшей свалки, находившейся в черте города. Мероприятия по реабилитации и реновации территории, проведённые более 45 лет назад, остаются актуальными в наше время и иллюстрируют необходимость применения методов архитектурно-ландшафтной реабилитации для такого типа городских территорий.

Основной задачей всех представленных проектов была максимальная реабилитация неэффективно использующихся антропогенных территорий с целью ликвидации отрицательного влияния на городскую среду. Весь проведённый комплекс архитектурно-ландшафтных мероприятий был направлен на максимальное восстановление естественного вида территорий.

\section{Преобразование антропогенных ландшафтов в общественно-деловой и торговый кластер}

Ключевая суть метода - частичная или, при возможности, полная реорганизация пассивных и слабоэффективных территорий и составляющих их комплексов. Удобное расположение в зоне магистралей городского значения, доступность общественного транспорта, возможность вовлечения в этот процесс большого количества людей, в том числе жителей ближайших районов, создают для девелоперов и инвесторов особую привлекательность. Одним из вариантов организации общественного пространства в здании бывшего цеха или целого завода, может быть создание музея или концертного зала с комплексным благоустройством прилегающей территории и самих сооружений. Повсеместная и комплексная реабилитация, затрагивающая и архитектурную, и ландшафтную составляющие, позволит максимально использовать реабилитированные территории в жизни города. При соблюдении всех аспектов реабилитированная территория позволит улучшить рекреационную, торговую, общественную и инвестиционную привлекательность отдельно взятого района. Одним из примеров такого преобразования может послужить опыт из мировой практики, а именно преобразование сети газометров, построенных в Вене в конце XIX века (рис. 3). Изначально эти огромные сооружения служили резервуарами для газа, но с конца XX века они перестали быть востребованными в промышленных целях, и всё техническое оборудование было демонтировано. Оставшаяся кирпичная оболочка и 90 тыс. кубометров пустого внутреннего пространства сохранялись как архитектурные памятники. В 1995 году было принято решение о полной реорганизации и приспособлении газометров под новые функции - в торговые, деловые и жилые помещения, а также о благоустройстве территории вокруг самих резервуаров с целью создания новой экологическиориентированной зоны.

Другими примерами служат бывшие промышленные предприятия на территории Чешской Республики. В городе

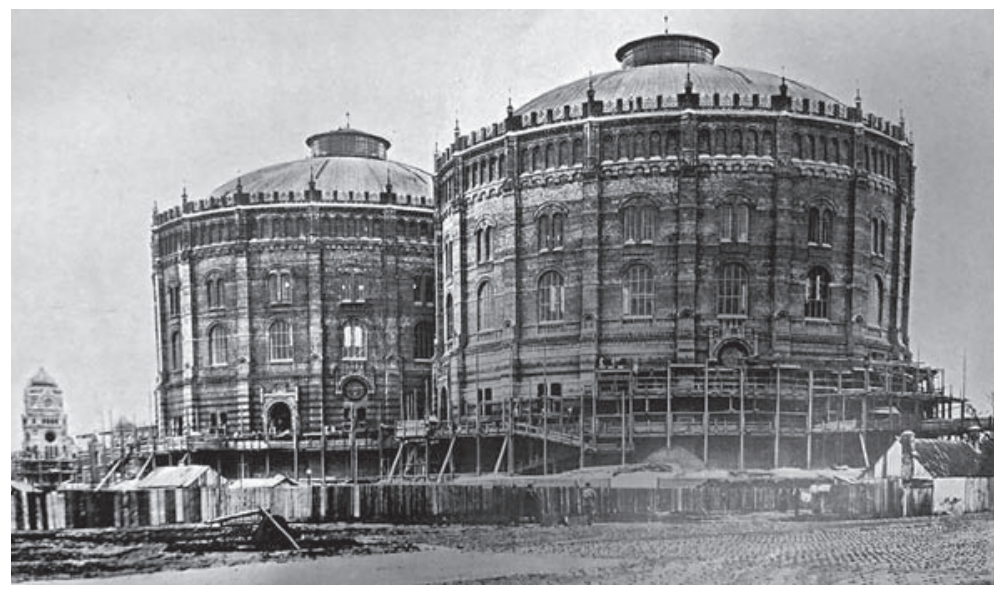

a)

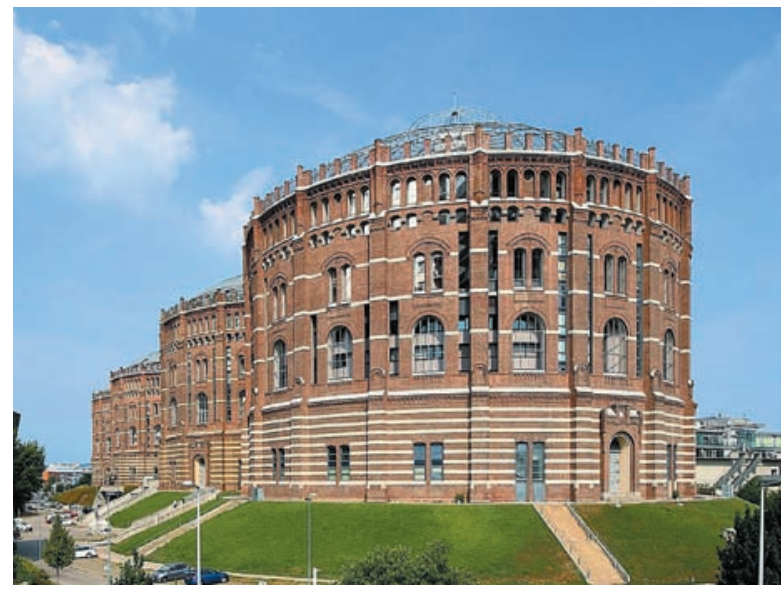

б)

Pис. 3. Преобразование промышленного кломплекса газометров в общественно-деловой, торговый и жилой кластер:внешний вид до реновации. Фото Франца Капауне (Franz Kapaune) конца ХХ века; б) современное состояние. Фото Эйгенеза Bерка (Eigenеs Werk) 
Острава бывшая территория Металлургического завода Витковице по переработке угля (основан в 1828 году; включен в новый список Европейского культурного наследия) была преобразована в общественную тематическую зону со смотровой площадкой, концертным залом, музейным комплексом (рис. 4). Чешское министерство культуры также официально номинировало металлургический завод Витковице в список культурного наследия ЮНЕСКО. Бывшая промышленная зона, ликвидированная в начале XXI века и являющаяся одной из градообразующих территорий, была удачно интегрирована в городскую ткань и стала примером реновации общественного пространства. Кроме реновации сооружений, были проведены мероприятия по ландшафтной реабилитации: геопластическое моделирование рельефа, частичная рекультивация, высадка новых деревьев и кустарников, как итог - максимальная интеграция промышленной территории в зелёный каркас города. Сохранённое индустриальное наследие в виде промышленных сооружений, взаимодействующих с разветвлённой ландшафтной структурой озеленённых пространств, позволило нейтрализовать негативное воздействие территории и создать качественно новую среду, комфортную как для жителей города, так и для туристов.

\section{Преобразование антропогенных ландшафтов в жилую застройку}

Промышленные предприятия в зависимости от их индустриального прошлого делятся на классы по степени опасности. Чем менее опасное производство находилось на рассматриваемых территориях, тем больше вариативность их реабилитации. Если территория бывшей индустриальной зоны была полностью санирована, отвечает санитарно-гигиеническим требованиям, предъявляемым к селитебным зонам, а бывшее производство на момент действия не относилось к средней и высокой степеням экологической опасности, возможна реновация её под жильё. Данный вид реабилитации наиболее популярен, так как в большинстве своём такие территории имеют очень выгодное расположение в городском контексте и в будущем становятся привлекательными с точки зрения инвестиций и продажи недвижимости. Однако важно отметить, что такое направление развития территорий приводит к значительному увеличению плотности населения и создаёт дополнительную нагрузку на инфраструктуру города. Дополнительная концентрация населения в одном месте вызывает дополнительную рекреационную нагрузку на природные территории города, что отрицательно отражается на принципах устойчивого развития и устойчивости природного каркаса [5]. Для минимизации негативной составляющей такого способа реабилитации необходимо создание дополнительных зелёных зон. Одним из таких примеров из отечественной практики является реновация бывшей территории завода «ЗИЛ». Созданный на месте антропогенного ландшафта парк «Тюфелева роща», несмотря на свой небольшой размер и явную диспропорцию относительно всей площади реабилитации, частично нивелирует отрицательные моменты, возникающие при сооружении такого масштабного строительного комплекса.

Описанные аспекты имеют и экономическое значение. Реабилитация территорий промышленных предприятий, представленных техногенными территориями со средним и высоким классом экологической опасности, требует существенных инвестиций на реорганизацию [6; 7]. В связи с этим возникает необходимость экологического обследования антропогенной территории, исходя из результатов которого можно выбрать наиболее предпочтительное направление дальнейшего развития.

Определение новых функциональных программ территорий бывших промышленных зон требует комплексного градостроительного обоснования. Приоритетное значение должны иметь экологические аспекты, направленные на сохранение и преумножение зелёного каркаса города. Это требует взаимодействия как органов городской администрации, так и заинтересованных инвесторов, и в первую очередь,

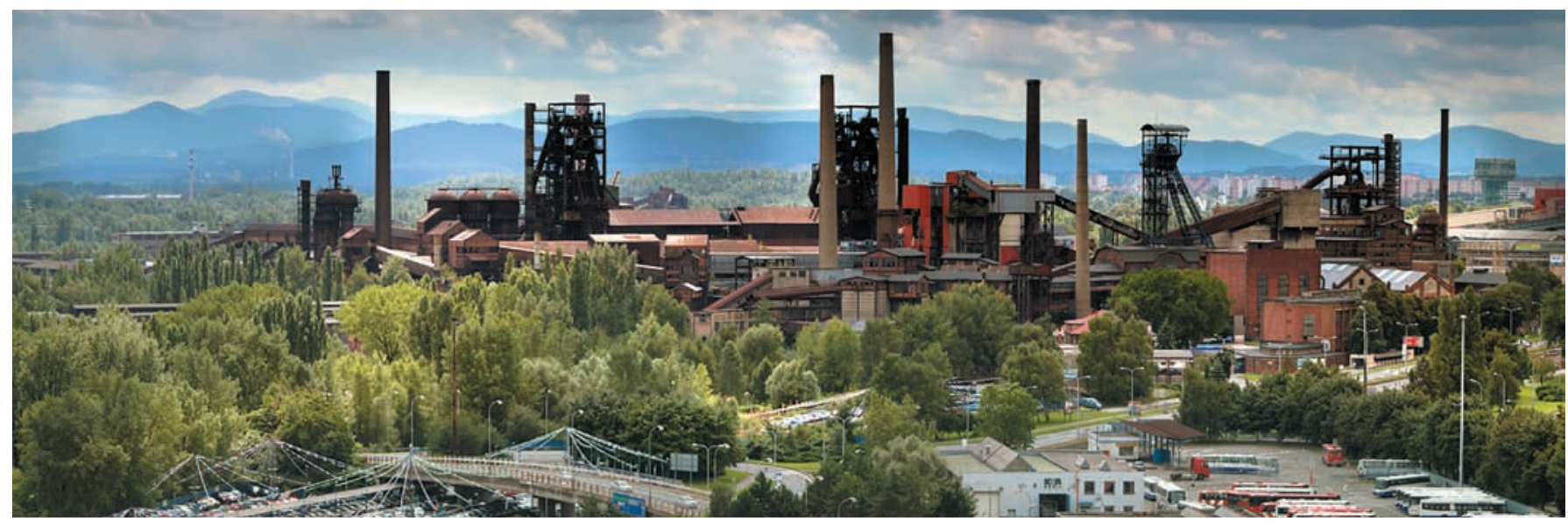

Pис. 4. Металлургический завод Витковище в городе Остраве (CzechRepublic). Фото - «DolniVitkovice» Gallery, 2014 год 
кроме политический воли и ресурсов, здесь необходим научный подход.

Оценка качества городской среды становится принципиально важной задачей как при планировании, так и при реализации любых мероприятий по реабилитации, реновации и обеспечению экологической безопасности. Проведение оценки степени благоприятности городской среды для населения необходимо:

- для разработки стратегии оптимального использования пассивных антропогенных территорий;

- для определения предельно допустимых функциональных (рекреационных) нагрузок для различных типов нарушенных территорий;

- для оценки состояния сохранившегося природного потенциала;

- для поиска новых путей развития после непрерывного антропогенного использования территорий;

Антропогенная деятельность является основным фактором изменения равновесия в экосистеме городской среды, в наибольшей степени это выражено в крупных городах, вблизи крупных магистралей, различных промышленных предприятий и других потенциально опасных объектов.

Для успешной и масштабной реабилитации антропогенных территорий в урбанизированном ландшафте важно придерживаться следующих принципов:

- принципа комплексного социально-экономического и экологического развития антропогенных территорий, направленного на повышение качества жизни нынешнего и будущих поколений;

- принципа устойчивого развития городской среды и эко-позитивности;

- принципа этапности решения проблем экологической безопасности, установления краткосрочных, среднесрочных и долгосрочных задач и их соответствия поставленным перед реабилитацией целям;

- принципа социально-экологической приоритетности в разработке и реализации проектов, направленных на развитие антропогенных территорий, улучшение социальных и экономических условий жизни населения;

- принципа наукоёмкости и технологичности для обеспечения рационального использования сохранившегося природного потенциала и экологической безопасности на основе научного и технологического прогресса, результатов теоретических исследований и зарубежного опыта;

- принципа информированности и вовлечённости для распространения информации об экологическом состоянии территории среди населения и обеспечения участия общественности в принятии решений при будущей реабилитации и реновации.

\section{Лuтература}

1. Щербина, E.В. Градостроительные аспекты проектирования устойчивой городской среды / Е.В. Щербина, Н.В.
Данилина // Вестник Иркутского государственного технического университета. - 2014. - № 11. - С. 183-186.

2. Sherbina, E.V. City planning issues for sustainable development / E.V. Sherbina, N.V. Danilina, D.N. Vlasov // International Journal of Applied Engineering Research. - 2015. - T. 10. No 22. - P. 43131-43138.

3. Глазычев, В.Л. Городская среда. Технология развития : настольная книга / В.Л. Глазычев, М.М. Егоров, Т.В. Ильина. - Москва : Ладья, 1995. - 240 с.

4. Innovative methods of anthropogenic landscape reconstruction in the urbanized oil and gas region environment / Bauer N.V., Shabatura L.No., Speranskaya N.I., Iatsevich O.E. // IOP Conference Series: Materials Science and Engineering : International Scientific-Practical Conference of Students, Graduate Students and Young Scientists "Transport and Storage of Hydrocarbons". Тюмень, 2016 // Procedia Engineering. 2016. - c. 1105-1111.

5. Слепнев, М.А. Методические подходы к подготовке документации по планировке особо охраняемых природных территорий / М.А. Слепнев, Е.В Щербина // Экология урбанизированных территорий. - 2015. - № 3. - С. 68-73.

6. Дубровина, М.В. Основные методы реновации производственных территорий. Обоснование направления градостроительного использования территорий бывших производственных зон // Научный журнал. Иваново. 2017. № 5 (18).

7. Щербина, E.B. Особенности размещения объектов недвижимости на площадях, занятых техногенными грунтами, после сноса старых зданий / Е.В. Щербина, И.В. Аверин, Е.И. Васильчик // Вестник МГСУ. - 2011. № 1-2. - С. 136-140.

\section{References}

1. Sherbina E. V., Danilina N. V. Gradostroitel'nye aspekty proektirovaniya ustoichivoi gorodskoi sredy [Town-planning aspects of designing a sustainable urban environment]. Vestnik irkutskogo gosudarstvennogo tekhnicheskogo universiteta [Bulletin of Irkutsk state technical University], 2014, no. 11, pp. 183-186.

2. Sherbina E.V., Danilina N.V., Vlasov D.N. City planning issues for sustainable development. International Journal of Applied Engineering Research, 2015, vol. 10, no. 22. (In Engl.)

3. Glazychev V.L., Egorov M.M., Ilyina T.V. Gorodskaya sreda. Tekhnologiya razvitiya : nastol'naya kniga [City environment. Development Technology : Handbook]. Moscow, Lad'ya Publ, 240 pages.

4. Bauer N.V., Shabatura L.N., Speranskaya N.I., Iatsevich O.E. Innovative methods of anthropogeniclandscape reconstruction in the urbanized region oil and gas environment. IOP Conference Series: Materials Science and Engineering Ser. "International Scientific-Practical Conference of Students, Graduate Students and Young Scientists 'Transport and Storage of Hydrocarbons ' ", Tyumen, 2016. Procedia Engineering, 2016, pp. 1105-1111..

5. Slepnev M.A., Sherbina E.V. Metodicheskie podkhody k podgotovke dokumentatsii po planirovke osobo okhranyaemykh 
prirodnykh territorii [Methodological approaches to the preparation of documentation for the planning of specially protected natural territories]. Ekologiya urbanizirovannykh territorii [Ecology of urbanized territories], 2015, no. 3, pp. 68-73.

6. Telichenko V.I., Potapov A.D., Shcherbina E.V. Nadezhnoe i effektivnoe stroitel'stvo na tekhnogenno-zagryaznennykh territoriyakh [Reliable and efficient construction on technogenic-contaminated territories]. Promyshlennoe $i$ grazhdanskoe stroitel'stvo [Industrial and civil construction], 1997, no. 8.

7. Sherbina E.V., Averin I.V., Vasilchik E.I. Osobennosti razmeshcheniya ob"ektov nedvizhimosti na ploshchadyakh zanyatykh tekhnogennymi gruntami posle snosa starykh zdanii [Features of placement of real estate objects on the areas occupied with technogenic soils after demolition of old buildings]. Vestnik MGSU, 2011, no. 1-2, pp. 136-140.

Прокофьева Екатерина Юрьевна (Москва). Кандидат архитектуры. Заведующая кафедрой «Ландшафтная архитектура» ФГБОУ В0 «Московский архитектурный институт (государственная академия)» (107031, Москва, улица Рождественка, дом 11. МАРХИ). Эл.почта: plant-arc@mail.ru.

Васильев Никита Вадимович (Москва). Аспирант ФГБОУ В0 «Московский архитектурный институт (государственная академия)» (107031, Москва, улица Рождественка, дом 11. МАРХИ). Эл.почта: niklucky1@yandex.ru.

Prokofieva Ekaterina Yuryevna (Moscow). Candidate of Architecture. Head of the Department of Landscape Architecture at the Moscow Institute of Architecture (State Academy) (11 Rozhdestvenka St., Moscow, 107031. MARCHI). E-mail: plant-arc@mail.ru.

Vasiliev Nikita Vadimovich (Moscow). Post-graduate student of the Moscow Institute of Architecture (State Academy) (11 Rozhdestvenka St., Moscow, 107031. MARCHI).E-mail: niklucky1@yandex.ru. 